\title{
Disability due to knee pain and somatising tendency in Japanese adults
}

\author{
Tomoko Fujii ${ }^{1}$, Hiroyuki Oka ${ }^{1 *}$, Junji Katsuhira ${ }^{2}$, Juichi Tonosu ${ }^{3}$, Satoshi Kasahara ${ }^{4}$, Sakae Tanaka ${ }^{5}$ \\ and Ko Matsudaira ${ }^{1}$
}

\begin{abstract}
Background: Knee pain is common and related to knee osteoarthritis. However, there is a discrepancy between knee pain and radiographic osteoarthritis. In the general population, knee pain is associated with psychological and cognitive factors, which would be one explanation for the discrepancy. Limited evidence demonstrates that somatization is associated with knee pain. This study examined the association between disability due to knee pain and a high somatising tendency.

Methods: Japanese adults (aged 20-64 years) who had experienced knee pain in the past four weeks were included in this study ( $n=14,695,50 \%$ women). Data were extracted from a large internet survey. Somatising tendency was assessed using the Somatic Symptom Scale-8 (SSS-8). Disability due to knee pain was categorized into three levels: 1) knee pain without difficulty with activities of daily living (ADL), 2) knee pain with ADL difficulty but without requiring sick leave, and 3 ) knee pain requiring sick leave. The association between $\geq$ high somatising tendency (SSS-8 score $\geq 12$ ) as well as very high somatising tendency (SSS-8 score $\geq 16$ ) and disability due to knee pain was examined using logistic regression models adjusted for age, sex, body mass index, depressive symptoms, education level, regular exercise, chronicity of knee pain ( $\geq 3$ months), osteoarthritis, rheumatoid arthritis, and fibromyalgia.
\end{abstract}

Results: Greater disability due to knee pain was associated with a higher odds ratio for $\geq$ high somatising tendency (adjusted odds ratio $(\mathrm{aOR})=2.36$ [2.10-2.66] in group 2 vs. group 1, $\mathrm{aOR}=3.23$ [2.66-3.92] in group 3 vs. group 1). Stronger associations were found for a very high somatising tendency ( $\mathrm{aOR}=2.80$ [2.42-3.23] in group 2 vs. group 1 , $\mathrm{aOR}=4.51$ [3.64-5.58] in group 3 vs. group 1).

Conclusions: Somatization may play a role in disability due to knee pain in the general adult population with knee pain, similar to the role of somatization in low back pain.

Keywords: Knee pain, Osteoarthritis of the knee, Somatising tendency

\section{Background}

Knee pain is a common symptom. The 12-month prevalence of knee pain was reported to be $29 \%$ in people who were 40-79 years old in Nottingham, UK [1]. In Japan, the prevalence of knee pain was reported to be $33 \%$ (men 28\%, women 35\%) in an integrated cohort in which most participants were 60 years of age or older [2]. In a cohort study of Japanese workers who were 19-64 years old, the one-month prevalence of knee pain was $12 \%$ [3].

\footnotetext{
* Correspondence: okah-tky@umin.ac.jp

${ }^{1}$ Department of Medical Research and Management for Musculoskeletal Pain, 22nd Century Medical \& Research Center, Faculty of Medicine, The University of Tokyo, 7-3-1 Hongo, Bunkyo-ku, Tokyo 113-8655, Japan

Full list of author information is available at the end of the article
}

One cause of knee pain is osteoarthritis (OA). However, there is a discrepancy between radiographic knee OA and knee pain; not all people with knee pain have radiographic knee OA, and not all people with knee OA have knee pain [4]. Recently, magnetic resonance imaging (MRI) of the knee has been studied in relation to knee pain $[5,6]$. However, even the structural changes assessed via MRI may not always explain knee pain [7]. Felson et al. emphasized the importance of separating the disease process of OA and the syndrome of musculoskeletal pain and disability, which is a common concept in low back pain [8].

Psychological factors predict the incidence, chronicity, and disability of low back pain [9-11]. Similarly, some evidence indicates that psychological factors are also 
associated with knee pain, which could be one of the explanations for the discrepancy between radiographic changes and knee pain [12, 13]. Somatization, one psychological factor, is "a tendency to experience and communicate somatic distress in response to psychosocial stress and to seek medical help for it" [14]. Somatization often coexists with depression and anxiety [15]. Somatising tendency is a predisposition to be more aware of and to worry about, common somatic symptoms [16]. Longitudinal studies have shown that somatising tendency is not merely a consequence of musculoskeletal pain but a risk factor for multisite musculoskeletal pain [3, 17]. A few studies have reported that somatising tendency was associated with knee pain $[3,18,19]$. However, evidence is limited regarding whether somatising tendency is associated with disability due to knee pain in the general population. This study aimed to examine whether the severity of disability due to knee pain is associated with a high somatising tendency in the general population of adults with knee pain.

\section{Methods \\ Participants}

Japanese adults aged 20-64 years with knee pain in the past four weeks $(n=14,695)$ were included in the present study. Data were extracted from a large internet survey of physical and mental health, which was conducted in February 2015. Participants were recruited by an internet research company, United Inc. (Tokyo, Japan), with which more than 1.37 million individuals across Japan have voluntarily registered. The only inclusion criterion for the survey was an age of 20-64 years. Of the approximately 1.25 million eligible individuals, 270,000 individuals were randomly selected and invited by e-mail to complete an online questionnaire. All respondents $(n=52,353)$ provided web-based informed consent and were compensated. Because the focus of this internet survey was not knee pain, the question regarding knee pain, which we created based on the typical question regarding low back pain, was generic. The question with an illustration showing the area of pain asked whether a participant had knee pain persisting for $\geq 1$ day in the past four weeks. The possible responses were as follows: 1) I did not have knee pain (KP0), 2) I had knee pain without difficulty with activities of daily living (ADL) (KP1), 3) I had knee pain with ADL difficulty but without requiring absence from social activities, such as work or school (KP2), and 4) I had knee pain requiring absence from social activities, such as work or school (KP3). Twenty-eight percent of the respondents $(n=14,695)$ answered that they had knee pain (KP1, 2, or 3). Only the individuals with knee pain were included in this analysis. Additionally, respondents were asked whether their knee pain lasted for $\geq 3$ months. The Institutional Review Board of the University of Tokyo approved this study.

\section{Assessments \\ Somatising tendency}

Somatising tendency was assessed using the Japanese version of the Somatic Symptom Scale-8 (SSS-8) [20]. The SSS- 8 is a self-administered questionnaire that assesses somatic symptom burden. The SSS-8 was developed as an abbreviated 8-item version of the Patient Health Questionnaire-15 (PHQ-15) to assess the presence and severity of common somatic symptoms [21]. The following somatic symptoms were assessed: 1) stomach or bowel problems; 2) back pain; 3) pain in the arms, legs, or joints; 4) headaches; 5) chest pain or shortness of breath; 6) dizziness; 7) feeling tired or having low energy; and 8) having trouble sleeping. The SSS8 was used as a reference measure in the Diagnostic and Statistical Manual of Mental Disorders (Fifth Edition) (DSM-5) field trials to facilitate the diagnosis of somatic symptom disorder [22]. The German version of the SSS-8 has good reliability and validity for the general German population [20]. We translated the English version of the SSS-8 into Japanese [23], and the Japanese version of the SSS-8 has been linguistically and psychometrically validated [24]. The total SSS-8 score was categorized, as in Gierk et al., into the following five groups: no to minimal (0-3); low (4-7); medium (8-11); high (12-15); and very high (16-32) [20].

\section{Covariates}

Demographic information was also collected in the survey. Body mass index (BMI) was calculated based on self-reported body weight and height as weight $(\mathrm{kg}) /$ height $(\mathrm{m})^{2}$. BMI was categorized into 3 levels $(<25,25-$ 29 , and $\geq 30$ ). The participants were asked whether they engaged in exercise regularly over the past year, such as walking and jogging, that lasted for $\geq 30 \mathrm{~min}$. The possible responses were none, 1-2 times per month, once per week, or more than twice per week. Engaging in regular exercise was defined as exercising more than twice per week. We also collected self-reported information on the chronic conditions for which the respondents were seeking treatment, including OA, rheumatoid arthritis (RA), and fibromyalgia.

Depressive symptoms were assessed using the Patient Health Questionnaire-2 (PHQ-2), an assessment composed of two questions from the Patient Health Questionnaire-9 [25]. The Japanese version of the Patient Health Questionnaire was previously validated [26]. The PHQ-2 assesses whether an individual has experienced depression and anhedonia within the past two weeks. Although each item is rated on a scale of $0-3$ in the original PHQ-2, the present study used the National 
Center of Neurology and Psychiatry version of the Japanese PHQ-2, which gives each item a binary response of yes or no (1/0) [26]. Therefore, the possible scores for the PHQ-2 were 0,1 , or 2 . Individuals who answer yes to at least one question are suspected of experiencing depression, and closer assessment of these individuals is recommended.

\section{Statistical analysis}

Initially, the demographic data were examined using descriptive statistics. The characteristics of the participants were compared according to three knee pain groups using the chi-square test. Whether the severity of disability due to knee pain was associated with $\geq$ high somatising tendency (SSS-8 score $\geq 12$ ) and very high somatising tendency (SSS-8 score $\geq 16$ ) was examined using logistic regression models. The outcome variables were 1) $\geq$ high and 2) very high somatising tendency, and they were analyzed in separate regression models. The independent variable was disability due to knee pain (3 levels). The participants who had knee pain without any ADL difficulty (KP1) were treated as the reference group. The chronicity of knee pain was also examined as an independent variable. The final multiple models were adjusted for age (5 levels), sex, BMI (3 levels), PHQ-2 (3 levels), education level (any college or no college), regular exercise (yes/no), and whether the participant was seeking treatment for OA, RA, or fibromyalgia. These potential confounders, which would be associated with both somatising tendency and knee pain and/or were adjusted for in previous studies, were chosen a priori based on the literature $[12,16,27,28]$. Multicollinearity was not suspected as all variance inflation factors (VIFs) were $<2$. The odds ratios (ORs) and their 95\% confidence intervals (CIs) were estimated. Analyses were conducted using SAS version 9.4 (SAS Institute, Inc., Cary, $\mathrm{NC}$, USA). All analyses were two-sided, and an $\alpha$-level of 0.05 was considered statistically significant.

\section{Results}

Participant characteristics are shown in Table 1. The mean age ( \pm standard deviation) was $45.6 \pm 11.9$ years, and half of the participants (49.5\%) were women. Among the participants with knee pain, most $(82.8 \%, n=12,161)$ had knee pain without any ADL difficulty (KP1), 13.3\% $(n=1954)$ had knee pain with ADL difficulty but without requiring sick leave $(\mathrm{KP} 2)$, and only $4.0 \%(n=580)$ reported using sick leave due to knee pain (KP3). Individuals in the greater disability group were more likely to be men, unmarried, and lack a college education. The proportion of participants with a PHQ-2 score of 2 was higher in the greater disability groups, and the proportion of participants with OA, RA, and fibromyalgia was also higher in the greater disability groups.
The proportion of participants with a high or very high somatising tendency was higher in the greater disability groups.

The results of the final logistic regression model are shown in Table 2. Disability due to knee pain was significantly associated both with $\geq$ high and very high somatising tendency after adjusting for age, sex, BMI, PHQ-2, education, regular exercise, OA, RA, fibromyalgia, and the chronicity of knee pain. The participants who had knee pain with ADL difficulty were more than twice as likely to have at least a high somatising tendency compared to those who had knee pain without difficulty (adjusted $\mathrm{OR}=2.36$ [2.10-2.66], $p<0.001$ ). Individuals who had knee pain requiring sick leave were more than three times as likely to have at least a high somatising tendency compared to those who had knee pain without ADL difficulty (adjusted OR $=3.23$ [2.66-3.92], $p<$ $0.001)$. The results for very high somatising tendency were similar, but stronger associations were found. The odds ratios for very high somatising tendency were 2.80 (95\% CI [2.42-3.23], $p<0.001)$ in the participants who had knee pain with ADL difficulty and 4.51 (95\% CI [3.64-5.58], $p<0.001)$ in the individuals who had knee pain requiring sick leave compared with those who had knee pain without ADL difficulty. Chronicity of knee pain was significantly associated with $\geq$ high somatising tendency $(\mathrm{OR}=1.28[1.16,1.41], p<0.001)$ but not with very high somatising tendency $(\mathrm{OR}=1.12[0.98$, 1.28], $p=0.103$ ).

\section{Discussion}

This study is the first to report a significant association between disability due to knee pain and high somatising tendency in Japanese adults. Individuals who had knee pain with difficulty in ADL were more than twice as likely to have a very high somatising tendency compared with those who had knee pain without difficulty in $\mathrm{ADL}$, and those who had knee pain requiring sick leave were more than four times as likely to have a high somatising tendency.

Knee pain is a common symptom, one cause of which is knee OA. However, a discrepancy between knee pain and radiographic knee OA has been observed [4]. A systematic review reported that this discordance can be partly explained by the fact that radiographic knee OA is often defined only based on anterior-posterior and/or lateral views, without a skyline view, which would miss knee OA in the patella-femoral joint [29]. The review also reported that the discordance varied according to the knee pain definition. However, the authors concluded that there was still discordance between knee pain and radiographic knee OA. Therefore, one approach involves separating knee pain and its related disability from the disease process of OA [8], which is a 
Table 1 Characteristics of the participants with knee pain

\begin{tabular}{|c|c|c|c|c|c|}
\hline & All $(n=14,695)$ & $\begin{array}{l}\text { Knee pain without difficulty } \\
\text { in } \operatorname{ADL}(n=12,161)\end{array}$ & $\begin{array}{l}\text { Knee pain with difficultly but } \\
\text { without sick leave }(n=1954)\end{array}$ & $\begin{array}{l}\text { Knee pain with sick } \\
\text { leave }(n=580)\end{array}$ & $p$-value $e^{*}$ \\
\hline Age (\%) & & & & & $<0.001$ \\
\hline $20-29$ & $1942(13.2)$ & 1569 (12.9) & $271(13.9)$ & $102(17.6)$ & \\
\hline $30-39$ & 2903 (19.8) & 2345 (19.3) & $411(21.0)$ & $147(25.3)$ & \\
\hline $40-49$ & 3462 (23.6) & $2875(23.6)$ & $441(22.6)$ & $146(25.2)$ & \\
\hline $50-59$ & $4322(29.4)$ & 3599 (29.6) & $588(30.1)$ & $135(23.3)$ & \\
\hline $60-64$ & $2066(14.1)$ & $1773(14.6)$ & $243(12.4)$ & $50(8.6)$ & \\
\hline $\operatorname{Sex}(\%)$ & & & & & 0.0003 \\
\hline Men & $7421(50.5)$ & $6082(50.0)$ & $1000(51.2)$ & $339(58.5)$ & \\
\hline Women & $7274(49.5)$ & $6079(50.0)$ & $954(48.8)$ & $241(41.6)$ & \\
\hline BMI (\%) & & & & & 0.0003 \\
\hline$<25$ & $11,078(75.4)$ & $9228(75.9)$ & $1431(73.2)$ & $419(72.2)$ & \\
\hline $25-29$ & $2811(19.1)$ & $2311(19.0)$ & $381(19.5)$ & $119(20.5)$ & \\
\hline$\geq 30$ & $806(5.5)$ & $622(5.1)$ & $142(7.3)$ & $42(7.2)$ & \\
\hline Marital status (\%) & & & & & $<0.001$ \\
\hline Not married & $6249(42.5)$ & $5069(41.7)$ & $884(45.2)$ & $296(51)$ & \\
\hline Married & 8446 (57.5) & $7092(58.3)$ & $1070(54.8)$ & $284(49)$ & \\
\hline Education (\%) & & & & & 0.003 \\
\hline No college & $7820(53.2)$ & $6402(52.6)$ & $1077(55.1)$ & $341(58.8)$ & \\
\hline Some college & $6875(46.8)$ & $5759(47.4)$ & $877(44.9)$ & $239(41.2)$ & \\
\hline Exercise (\%) & & & & & 0.016 \\
\hline No regular exercise & $11,585(78.8)$ & 9577 (78.8) & $1524(78)$ & $484(83.5)$ & \\
\hline Regular exercise & $3110(21.2)$ & $2584(21.3)$ & $430(22)$ & 96 (16.6) & \\
\hline PHQ-2 (\%) & & & & & $<0.001$ \\
\hline 0 & $9415(64.1)$ & $8028(66.0)$ & $1060(54.3)$ & $327(56.4)$ & \\
\hline 1 & $2546(17.3)$ & 2054 (16.9) & $399(20.4)$ & $93(16.0)$ & \\
\hline 2 & $2734(18.6)$ & $2079(17.1)$ & $495(25.3)$ & $160(27.6)$ & \\
\hline Chronic knee pain (\%) & & & & & $<0.001$ \\
\hline No & 4906 (33.4) & 4096 (33.7) & $509(26.1)$ & 301 (51.9) & \\
\hline Yes & 9789 (66.6) & $8065(66.3)$ & $1445(74.0)$ & $279(48.1)$ & \\
\hline Osteoarthritis (\%) & $607(4.1)$ & $328(2.7)$ & $209(10.7)$ & $70(12.1)$ & $<0.001$ \\
\hline Rheumatoid arthritis (\%) & 229 (1.6) & $138(1.1)$ & $67(3.4)$ & $24(4.1)$ & $<0.001$ \\
\hline Fibromyalgia (\%) & $81(0.6)$ & $38(0.3)$ & $27(1.4)$ & $16(2.8)$ & $<0.001$ \\
\hline SSS-8 (\%) & & & & & $<0.001$ \\
\hline No to minimal & $5262(35.8)$ & 4679 (38.5) & $418(21.4)$ & $165(28.5)$ & \\
\hline Low & 4175 (28.4) & $3542(29.1)$ & $526(26.9)$ & $107(18.5)$ & \\
\hline Medium & $2510(17.1)$ & $2069(17.0)$ & $363(18.6)$ & $78(13.5)$ & \\
\hline High & $1434(9.8)$ & 1079 (8.9) & $284(14.5)$ & $71(12.2)$ & \\
\hline Very high & $1314(8.9)$ & 792 (6.5) & 363 (18.6) & 159 (27.4) & \\
\hline
\end{tabular}

$A D L$ activities of daily living, $B M I$ body mass index, PHQ-2 Patient Health Questionnaire-2, SSS-8 Somatic Symptom Scale-8 ${ }^{*} p$-value from the chi-square test

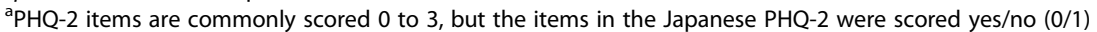

concept similar to that used for low back pain. Knee pain and knee OA share some risk factors, such as older age, being overweight, and having previous knee injuries
[28, 30]. In addition, psychological factors, such as depression and somatising tendency, seem to play some role in knee pain, which could be one explanation for 
Table 2 Associations between high (SSS-8 $\geq 12$ ) or very high somatising tendency (SSS-8 $\geq 16$ ) and disability due to knee pain from multiple logistic regression models $(n=14,695)$

\begin{tabular}{|c|c|c|c|c|c|c|}
\hline & \multicolumn{3}{|l|}{$S S S 8 \geq 12$} & \multicolumn{3}{|l|}{ SSS8 $\geq 16$} \\
\hline & $\mathrm{OR}\left[95 \% \mathrm{Cl}^{\mathrm{a}}\right.$ & $p$-value & Type $3 p$-value & $\mathrm{OR}[95 \% \mathrm{CI}]^{\mathrm{a}}$ & $p$-value & Type 3 p-value \\
\hline Disability due to pain & & & $<0.001$ & & & $<0.001$ \\
\hline Knee pain without difficulty in ADL & 1 & & & 1 & & \\
\hline Knee pain with difficulty but without sick leave & $2.36[2.10,2.66]$ & $<0.001$ & & $2.80[2.42,3.23]$ & $<0.001$ & \\
\hline Knee pain with sick leave & $3.23[2.66,3.92]$ & $<0.001$ & & $4.51[3.64,5.58]$ & $<0.001$ & \\
\hline Chronic knee pain yes vs. no & $1.28[1.16,1.41]$ & $<0.001$ & & $1.12[0.98,1.28]$ & 0.103 & \\
\hline
\end{tabular}

SSS-8 Somatic Symptom Scale-8, OR odds ratio, $\mathrm{Cl}$ confidence interval, $A D L$ activities of daily living

${ }^{a}$ Adjusted for age, sex, body mass index, depressive symptoms (Patient Health Questionnaire-2 (PHQ-2)), education, regular exercise, osteoarthritis, rheumatoid arthritis, and fibromyalgia

the discrepancy between radiographic changes and knee pain $[12,13]$. Assessing these psychological factors may help predict the onset and prognosis of knee pain in general and occupational health practices.

The results of the current study add to those of the few previous studies that found an association between somatising tendency and knee pain. As part of a large international survey of musculoskeletal symptoms (the Cultural and Psychosocial Influences on Disability [CUPID] study), Matsudaira et al. used a selfadministered questionnaire in Japanese to examine pain in six anatomical regions [3]. Somatising tendency was assessed using a subset of items from the Brief Symptom Inventory [31]. The odds of experiencing any knee pain or disabling knee pain in the past month was approximately three times higher in the participants who had $\geq 2$ distressing somatic symptoms compared to those who had no such somatic symptoms. In the CUPID study in Sri Lanka, a similar but weaker association was found, with a prevalence ratio of 1.8 [19]. These two studies were cross-sectional reports, and the causal direction was unknown. Palmer et al. followed workingaged subjects for 18 months in a postal survey in the UK [18]. A higher somatising tendency was associated with new onset of knee pain and its persistence. The present study further suggests the possibility that a high somatising tendency may lead to greater disability and sick leave utilization in people with knee pain.

The factors associated with disability in knee OA patients have been reported in the literature. Older age, female sex, lower social class, obesity, lower quadriceps strength, comorbid health problems, helplessness, and knee pain severity (rather than radiographic severity) were associated with disability or worsening of physical function in people with knee OA [32-36]. Reduced work productivity is typically assessed in terms of absenteeism (days off from work) and presentieesm (productivity loss while at work). A study on reduced work productivity due to knee problems found that a low 12-Item Short Form Health Survey (SF-12) Physical Component Summary score, semi-manual labor or manual labor, and a high maximum knee pain score were associated with presenteeism in people with chronic knee pain and joint space narrowing [37]. A low SF-12 Mental Component Summary score was associated with absenteeism in this study, although reduced work productivity was primarily attributed to presenteeism. For low back pain, the risk factors for chronicity/disability have been extensively studied and are reflected in the guidelines for the management of low back pain [38]. Psychological distress, depressive mood, somatization, work-related factors, pain severity, functional impact, and prior episodes of low back pain have all been reported as prognostic factors [38]. In a recent prospective study, baseline disability, age, and somatization were independently associated with follow-up disability in patients with chronic low back pain [39]. Our results suggest that the factors associated with disability due to knee pain in the general population may not be the same as those in knee OA patients. Somatising tendency may play some role in disability due to knee pain, which is similar to low back pain. When there is a large discrepancy between radiographic changes and knee pain-related disability, it may be useful for clinicians to assess the patient's somatising tendency and consider a potential psychological approach.

It is plausible that individuals with a high somatising tendency are more aware of and worry about their knee symptoms and consequently avoid activities that may exacerbate their symptoms [40]. Avoidance behavior may result in disuse and disability. In a previous study, somatising tendency was associated with knee pain especially when the pain was chronic or disabling, although the study was cross-sectional [41]. Therefore, somatising tendency is speculated to be more important for disability related to knee pain rather than the occurrence of knee pain. However, due to the cross-sectional design of the current study, this conclusion cannot be determined. Future longitudinal studies are needed.

Chronicity of knee pain was associated with $\geq$ high somatising tendency but not with a very high somatising tendency. A prospective study found an association between baseline somatising tendency and knee pain 
persistence [18]. Chronic pain should lead to greater concern regarding the symptom. Determining a conclusion from our results is difficult. People often experience knee pain intermittently. We inquired only about knee pain occurring within the past four weeks. Therefore, it is possible that a participant who did not have chronic knee pain in the past four weeks experienced chronic knee pain previously. Prospective studies are needed to examine the association between somatising tendency and the course of disability due to knee pain.

The strength of the present study is its large sample size with information on relevant covariables. The participants were not recruited in clinical settings; therefore, the possibility of bias due to seeking medical treatment should be low. However, some limitations should be noted. Due to the cross-sectional study design, the causal direction of the association between disability due to knee pain and somatising tendency is unknown. In the survey participants who did not have knee pain and were not included in this study $(n=37,658)$, the proportions of subjects in the SSS- 8 categories of no to minimal, low, medium, high, and very high were $63.8 \%, 21.4 \%, 8.6 \%, 3.4 \%$, and $2.8 \%$ respectively, and the proportions of these subjects with high and very high somatising tendencies were much lower than those of the subjects with knee pain. Because the SSS-8 questions assess joint pain, SSS- 8 scores should be higher in people with knee pain than those in people without knee pain. In addition, we suspected that chronicity of knee pain was an important covariate that should be examined with disability due to knee pain simultaneously in the regression models. Therefore, we included only the participants with knee pain. Individuals with more disabling knee pain would have had higher SSS-8 scores than those who had knee pain without ADL difficulty. However, the definition of a very high somatising tendency was a high SSS-8 score $(\geq 16)$. Therefore, we believe that the very high somatising tendency in these participants would not be solely attributed to knee pain. Because the focus of our internet survey was not knee pain, standard questionnaires regarding knee pain and function, such as the Western Ontario and McMaster Universities Osteoarthritis Index (WOMAC), were not used [42]. The questions and responses regarding knee pain and disability in the survey were generic to reduce the burden on the survey participants. Usually, PHQ-2 items are scored 0-3, but the Japanese version of the PHQ-2 used in our study has only binary responses. Although this questionnaire is recommended as a screening tool to assess the necessity of further evaluation for depression by the National Center of Neurology and Psychiatry, misclassification is possible, which would be non-differential. Finally, the participants in the present study were recruited online; therefore, our results may not be generalizable to the general Japanese population.

\section{Conclusion}

High somatising tendency was associated with greater disability due to knee pain in adults. Assessing and addressing somatising tendency may help predict patient outcomes and facilitate the treatment of patients with knee pain in general clinical practice.

\begin{abstract}
Abbreviations
ADL: Activities of daily living; BMI: Body mass index; Cl: Confidence interval; CUPID study: Cultural and Psychosocial Influences on Disability study; DSM5: Diagnostic and Statistical Manual of Mental Disorders (Fifth Edition); MRI: Magnetic resonance imaging; OA: Osteoarthritis; OR: Odds ratio; PHQ-15: Patient Health Questionnaire-15; PHQ-2: Patient Health Questionnaire-2; RA: Rheumatoid arthritis; SF-12: 12-Item Short Form Health Survey; SSS-8: Somatic Symptom Scale-8; VIFs: Variance inflation factors; WOMAC: Western Ontario and McMaster Universities Osteoarthritis Index
\end{abstract}

\section{Acknowledgements}

We would like to thank American Journal Experts for providing editorial assistance.

\section{Funding}

This study was conducted as a collaborative research study between the University of Tokyo and Eli Lilly Japan (https://www.lilly.co.jp/). Eli Lilly Japan K.K. funded this study. The funder had no role in the study design, data collection and analysis, decision to publish, or preparation of the manuscript.

\section{Availability of data and materials}

The datasets used and/or analyzed during the current study are available from the corresponding author upon request.

\section{Authors' contributions}

KM conceived and planned the internet survey of physical and mental health. $\mathrm{HO}$ contributed to the data acquisition. TF analyzed and interpreted the data and drafted the manuscript. KM, HO, ST, JK, JT, and SK critically reviewed the manuscript. All authors read and approved the final manuscript.

\section{Ethics approval and consent to participate}

All participants provided web-based informed consent, and this study was approved by the Institutional Review Board of the University of Tokyo.

\section{Consent for publication}

Not applicable.

\section{Competing interests}

All authors have declared the following potential conflicts of interest. KM received the following support: a research grant from the Ministry of Health, Labour and Welfare for the submitted work; grant support, including an endowed chair from Sumitomo Dainippon Pharma Co., Ltd. and Okamura Corporation; grant support, including an endowed chair and lecture fees from AYUMI Pharmaceutical Corporation, Nippon Zoki Pharmaceutical Co., Ltd., Ono Pharmaceutical Co., LTD., Eli Lilly Japan K.K., Astellas Pharma Inc., TOTO LTD., and Eisai Co., Ltd.; lecture fees from Pfizer Japan Inc., Hisamitsu Pharmaceutical Co., Inc., Janssen Pharmaceutical K.K., Kaken Pharmaceutical Co., LTD., and Teijin Pharma Limited; and lecture fees and advisory fees from Shionogi \& Co., Ltd. outside the submitted work. HO received grants from Teijin Pharma Limited, Pfizer Inc., and Fujifilm Medical Co., Ltd.; grants and personal fees from AYUMI Pharmaceutical Corporation, Nippon Zoki Pharmaceutical Co., Ltd., and Ono Pharmaceutical Co., LTD.; and grants from Eli Lilly Japan K.K. outside the submitted work. ST received personal fees for expert testimony from Amgen Inc., Asahi Kasei Pharma Corporation, Amgen Astellas BioPharma K.K., Ono Pharmaceutical Co., LTD., Kyocera Medical Corporation, Daiichi Sankyo Company, Limited, Teijin Pharma Limited, Eli Lilly Japan K.K., and Pfizer Japan Inc.; endowments from Astellas Pharma Inc., AYUMI Pharmaceutical Corporation, Pfizer Japan Inc., Bristol-Myers Squibb, Daiichi Sankyo Company, Limited, and Chugai Pharmaceutical Co., Ltd.; and grants from the Japan Agency for Medical Research and Development (AMED), the Japan Society for the Promotion of Science (JSPS)/Grant-in-aid for Scientific Research (A), and the Japan Society for the Promotion of 
Science (JSPS)/Grant-in-aid for Exploratory Research outside the submitted work. TF, JK, JT, and SK have no competing interests to report.

\section{Publisher's Note}

Springer Nature remains neutral with regard to jurisdictional claims in published maps and institutional affiliations.

\section{Author details}

'Department of Medical Research and Management for Musculoskeletal Pain, 22nd Century Medical \& Research Center, Faculty of Medicine, The University of Tokyo, 7-3-1 Hongo, Bunkyo-ku, Tokyo 113-8655, Japan. ${ }^{2}$ Department of Prosthetics \& Orthotics and Assistive Technology, Faculty of Medical Technology, Niigata University of Health and Welfare, 1398 Shimami-cho, Kita-ku, Niigata-shi, Niigata 950-3198, Japan. ${ }^{3}$ Department of Orthopaedic Surgery, Kanto Rosai Hospital, 1-1 Kizukisumiyoshi-cho, Nakahara-ku, Kawasaki City, Kanagawa 211-8510, Japan. ${ }^{4}$ Department of Pain and Palliative Medicine, Faculty of Medicine, The University of Tokyo, 7-3-1 Hongo, Bunkyo-ku, Tokyo 113-8655, Japan. ${ }^{5}$ Department of Orthopaedic Surgery, Faculty of Medicine, The University of Tokyo, 7-3-1 Hongo, Bunkyo-ku, Tokyo 113-8655, Japan

\section{Received: 16 August 2017 Accepted: 14 January 2018}

\section{Published online: 19 January 2018}

\section{References}

1. O'Reilly SC, Muir KR, Doherty M. Knee pain and disability in the Nottingham community: association with poor health status and psychological distress. Br J Rheumatol. 1998;37(8):870-3.

2. Yoshimura N, Akune T, Fujiwara S, Shimizu Y, Yoshida H, Omori G, Sudo A, Nishiwaki Y, Yoshida M, Shimokata H, et al. Prevalence of knee pain, lumbar pain and its coexistence in Japanese men and women: the longitudinal cohorts of motor system organ (LOCOMO) study. J Bone Miner Metab. 2014;32(5):524-32.

3. Matsudaira K, Palmer KT, Reading I, Hirai M, Yoshimura N, Coggon D. Prevalence and correlates of regional pain and associated disability in Japanese workers. Occup Environ Med. 2011:68(3):191-6.

4. Hannan MT, Felson DT, Pincus T. Analysis of the discordance between radiographic changes and knee pain in osteoarthritis of the knee. J Rheumatol. 2000;27(6):1513-7.

5. Hunter DJ, Guermazi A, Roemer F, Zhang Y, Neogi T. Structural correlates of pain in joints with osteoarthritis. Osteoarthr Cartil. 2013;21(9):1170-8.

6. Joseph GB, Hou SW, Nardo L, Heilmeier U, Nevitt MC, McCulloch CE, Link TM. MRI findings associated with development of incident knee pain over 48 months: data from the osteoarthritis initiative. Skelet Radiol. 2016;45(5): 653-60

7. Javaid MK, Kiran A, Guermazi A, Kwoh CK, Zaim S, Carbone L, Harris T, McCulloch CE, Arden NK, Lane NE, et al. Individual magnetic resonance imaging and radiographic features of knee osteoarthritis in subjects with unilateral knee pain: the health, aging, and body composition study. Arthritis Rheum. 2012; 64(10):3246-55

8. Felson DT, Lawrence RC, Dieppe PA, Hirsch R, Helmick CG, Jordan JM, Kington RS, Lane NE, Nevitt MC, Zhang Y, et al. Osteoarthritis: new insights. Part 1: the disease and its risk factors. Ann Intern Med. 2000;133(8):635-46.

9. Pinheiro MB, Ferreira ML, Refshauge $K$, Ordonana JR, Machado GC, Prado LR, Maher CG, Ferreira PH. Symptoms of depression and risk of new episodes of low back pain: a systematic review and meta-analysis. Arthritis care \& research. 2015;67(11):1591-603.

10. Taylor JB, Goode AP, George SZ, Cook CE. Incidence and risk factors for firsttime incident low back pain: a systematic review and meta-analysis. Spine J. 2014;14(10):2299-319.

11. Pincus T, Burton AK, Vogel S, Field AP. A systematic review of psychological factors as predictors of chronicity/disability in prospective cohorts of low back pain. Spine. 2002;27(5):E109-20.

12. Phyomaung PP, Dubowitz J, Cicuttini FM, Fernando S, Wluka AE, Raaijmaakers $P$, Wang Y, Urquhart DM. Are depression, anxiety and poor mental health risk factors for knee pain? A systematic review. BMC Musculoskelet Disord. 2014;15:10.

13. Urquhart DM, Phyomaung PP, Dubowitz J, Fernando S, Wluka AE, Raajmaakers P, Wang Y, Cicuttini FM. Are cognitive and behavioral factors associated with knee pain? A systematic review. Semin Arthritis Rheum. 2015;44(4):445-55
14. Lipowski ZJ. Somatization: the concept and its clinical application. Am J Psychiatry. 1988:145(11):1358-68.

15. Lowe B, Spitzer RL, Williams JB, Mussell M, Schellberg D, Kroenke K. Depression, anxiety and somatization in primary care: syndrome overlap and functional impairment. Gen Hosp Psychiatry. 2008;30(3):191-9.

16. Vargas-Prada S, Coggon D. Psychological and psychosocial determinants of musculoskeletal pain and associated disability. Best Pract Res Clin Rheumatol. 2015;29(3):374-90.

17. Solidaki E, Chatzi L, Bitsios P, Markatzi I, Plana E, Castro F, Palmer K, Coggon D, Kogevinas M. Work-related and psychological determinants of multisite musculoskeletal pain. Scand J Work Environ Health. 2010;36(1):54-61.

18. Palmer KT, Reading I, Calnan M, Linaker C, Coggon D. Does knee pain in the community behave such as a regional pain syndrome? Prospective cohort study of incidence and persistence. Ann Rheum Dis. 2007;66(9):1190-4.

19. Warnakulasuriya SS, Peiris-John RJ, Coggon D, Ntani G, Sathiakumar N, Wickremasinghe AR. Musculoskeletal pain in four occupational populations in Sri Lanka. Occupational medicine (Oxford, England). 2012;62(4):269-72.

20. Gierk B, Kohlmann S, Kroenke K, Spangenberg L, Zenger M, Brahler E, Lowe B. The somatic symptom scale-8 (SSS-8): a brief measure of somatic symptom burden. JAMA Intern Med. 2014;174(3):399-407.

21. Kroenke K, Spitzer RL, Williams JB. The PHQ-15: validity of a new measure for evaluating the severity of somatic symptoms. Psychosom Med. 2002; 64(2):258-66.

22. Narrow WE, Clarke DE, Kuramoto SJ, Kraemer HC, Kupfer DJ, Greiner L, Regier DA. DSM-5 field trials in the United States and Canada, part III: development and reliability testing of a cross-cutting symptom assessment for DSM-5. Am J Psychiatry. 2013;170(1):71-82.

23. Matsudaira K, Kawaguchi M, Murakami M, Fukudo S, Hashizume M, Oka H, Löwe B. Development of a linguistically validated Japanese version of the somatic symptom Scale-8 (SSS-8). Jpn J Psychosom Med. 2016;56(9):931-7.

24. Matsudaira K, Oka H, Kawaguchi M, Murakami M, Fukudo S, Hashizume M, Lowe B. Development of a Japanese version of the somatic symptom Scale8: psychometric validity and internal consistency. Gen Hosp Psychiatry. 2017:45:7-11.

25. Kroenke K, Spitzer RL, Williams JB. The patient health Questionnaire-2: validity of a two-item depression screener. Med Care. 2003:41 (11):1284-92.

26. Muramatsu K, Miyaoka H, Kamijima K, Muramatsu Y, Yoshida M, Otsubo T, Gejyo F. The patient health questionnaire, Japanese version: validity according to the mini-international neuropsychiatric interview-plus. Psychol Rep. 2007; 101(3 Pt 1):952-60.

27. Vargas-Prada S, Coggon D, Ntani G, Walker-Bone K, Palmer KT, Felli VE, Harari R, Barrero LH, Felknor SA, Gimeno D, et al. Descriptive epidemiology of Somatising tendency: findings from the CUPID study. PLoS One. 2016;11(4): e0153748.

28. Miranda H, Viikari-Juntura E, Martikainen R, Riihimaki H. A prospective study on knee pain and its risk factors. Osteoarthr Cartil. 2002;10(8):623-30.

29. Bedson J, Croft PR. The discordance between clinical and radiographic knee osteoarthritis: a systematic search and summary of the literature. BMC Musculoskelet Disord. 2008:9:116.

30. Blagojevic M, Jinks C, Jeffery A, Jordan KP. Risk factors for onset of osteoarthritis of the knee in older adults: a systematic review and meta-analysis. Osteoarthritis and cartilage / OARS, Osteoarthritis Research Society. 2010:18(1):24-33.

31. Derogatis $L R$, Melisaratos $N$. The brief symptom inventory: an introductory report. Psychol Med. 1983:13(3):595-605.

32. Creamer $P$, Lethbridge-Cejku $M$, Hochberg MC. Factors associated with functional impairment in symptomatic knee osteoarthritis. Rheumatology (Oxford, England). 2000;39(5):490-6.

33. McAlindon TE, Cooper C, Kirwan JR, Dieppe PA. Determinants of disability in osteoarthritis of the knee. Ann Rheum Dis. 1993:52(4):258-62.

34. Jordan JM, Luta G, Renner JB, Linder GF, Dragomir A, Hochberg MC, Fryer JG. Self-reported functional status in osteoarthritis of the knee in a rural southern community: the role of sociodemographic factors, obesity, and knee pain. Arthritis Care Res. 1996;9(4):273-8.

35. Peters TJ, Sanders C, Dieppe P, Donovan J. Factors associated with change in pain and disability over time: a community-based prospective observational study of hip and knee osteoarthritis. Br J Gen Pract. 2005;55(512):205-11.

36. de Rooij M, van der Leeden M, Heymans MW, Holla JF, Hakkinen A, Lems WF, Roorda LD, Veenhof C, Sanchez-Ramirez DC, de Vet HC, et al. Prognosis of pain and physical functioning in patients with knee osteoarthritis: a systematic review and meta-analysis. Arthritis care \& research. 2016;68(4):481-92. 
37. Agaliotis M, Fransen M, Bridgett L, Nairn L, Votrubec M, Jan S, Heard R, Mackey M. Risk factors associated with reduced work productivity among people with chronic knee pain. Osteoarthr Cartil. 2013;21(9):1160-9.

38. Airaksinen O, Brox Jl, Cedraschi C, Hildebrandt J, Klaber-Moffett J, Kovacs F, Mannion AF, Reis S, Staal JB, Ursin H, et al. Chapter 4. European guidelines for the management of chronic nonspecific low back pain. Eur Spine J. 2006;15(Suppl 2):S192-300.

39. Jegan NR, Brugger M, Viniol A, Strauch K, Barth J, Baum E, Leonhardt C, Becker A. Psychological risk and protective factors for disability in chronic low back pain - a longitudinal analysis in primary care. BMC Musculoskelet Disord. 2017;18(1):114

40. Vargas-Prada S, Martinez JM, Coggon D, Delclos G, Benavides FG, Serra C. Health beliefs, low mood, and somatising tendency: contribution to incidence and persistence of musculoskeletal pain with and without reported disability. Scand J Work Environ Health. 2013:39(6):589-98.

41. Palmer KT, Calnan M, Wainwright D, Poole J, O'Neill C, Winterbottom A, Watkins C, Coggon D. Disabling musculoskeletal pain and its relation to somatization: a community-based postal survey. Occupational medicine (Oxford, England). 2005;55(8):612-7.

42. Bellamy N, Buchanan WW, Goldsmith CH, Campbell J, Stitt LW. Validation study of WOMAC: a health status instrument for measuring clinically important patient relevant outcomes to antirheumatic drug therapy in patients with osteoarthritis of the hip or knee. J Rheumatol. 1988;15(12):1833-40.

\section{Submit your next manuscript to BioMed Central and we will help you at every step:}

- We accept pre-submission inquiries

- Our selector tool helps you to find the most relevant journal

- We provide round the clock customer support

- Convenient online submission

- Thorough peer review

- Inclusion in PubMed and all major indexing services

- Maximum visibility for your research

Submit your manuscript at www.biomedcentral.com/submit 